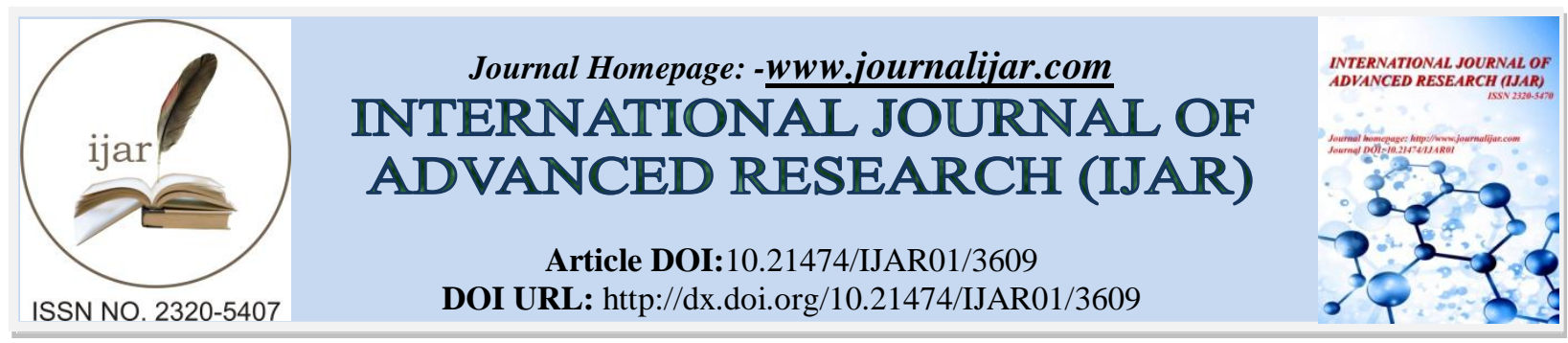

RESEARCH ARTICLE

\title{
AN ANALYTICAL STUDY ON THE RESULTS OF POSTERIOR FOSSA DECOMPRESSION AND LAX DUROPLASTY IN CHIARI 1 MALFORMATIONS.
}

Dr. R Saravana santosh kumar, Dr. M M Sankar and Dr. S Rajkumar.

\section{Manuscript Info}

Manuscript History

Received: 06 January 2017

Final Accepted: 09 February 2017

Published: March 2017

\section{Abstract}

\section{Introduction:-}

Chiari 1 malformation has been approximately diagnosed in $1 \%$ to $4 \%$ of patientsundergoingbrainorcervicalspine magnetic resonance imaging (MRI) studies,1,2. Chiari malformation type 1 (CM-1) is a common and often debilitating neurosurgical condition. In recent years, there has been a growing emphasis on outcomes research, including efforts to compare the results of various surgical approaches.3,4 To help facilitate more objective comparisons,severalgroupshaveproducedand/or validated different metrics to evaluate treatment outcomes.5-8 However, despite this growing interest in improved research methodology, evidencebased guidelines for surgical intervention are undefined. The decision to treat CM-1 surgically may be based on a variety of considerations, such as anticipated syrinx improvement and stabilization of spinal cord damage, as well as the risk of postoperative complications. The objective of this study was to use clinical and neuroimaging features to predict long-term patient-reported Quality of life outcomes in patients undergoing posterior fossa decompressions.

\section{Methods:-}

\section{Patient population:-}

This study is an analysis on the 28 patients evaluated and managed in our department of Neurosurgery in Govt Stanley medical college hospital, Chennai for Chiari 1 malformationsbetween 2011-2016. The study was proceeded following the approval from the ethical committee from our institution and consent from the patients.All patients had a detailed neurological examination followed by MRI scans of the brain with whole spine screening to evaluate the clinical presentations. Chiari 1 malformation patients had been graded based on the chiari severity index and underwent posterior fossa decompression with lax duroplasty.

\section{Data collection:-}

Preoperative signs and symptoms were recorded on admission. These findings were subsequently grouped into 3 categories 1) classic Chiari headaches (including occipital, Valsalva-induced, posttussive, and exertional headaches), 2) atypical presentation(frontotemporal headaches; and poorly localized headaches) 3) myelopathic predominant. We defined myelopathic symptoms as numbness, weakness, hyperreflexia, or unsteady gait.

Radiological analysis with MRI craniovertebral junction was used mainly to analyse the extent of descent of cerebellar tonsils and the size of the syrinx. In addition to these, we recorded the following neuroimaging parameters potentially related to CM-1 pathology: (1) tonsillar ectopia, as the perpendicular distance from the tipof the cerebellar tonsil to McRae's line9,10; (2) clivus-canal angle, as the angle between 
Wackenheim'sclivusbaselineandtheposteriorC2vertebralbodyline18; (3) dens angle, as the angle formed by a line through the $\mathrm{C} 2$ synchondrosis and a line through the odontoid tip measured from the posterior aspect of the $\mathrm{C} 2$ vertebral body11; (4) pB-C2, as the perpendicular distance between the ventral dura and a line joining the basion to the inferoposterior C2 body17,19,20; (5) obex position, as the distance between the obex and foramen magnum (basion-opisthion line)12; and (6) basilar invagination, as present when the tip of the dens was $5 \mathrm{~mm}$ above the Chamberlain's line.11 We defined a syrinx a contiguousspinalcordcavitationmeasuringatleast 3 mminmaximum diameter on T2-weighted MRI.

\section{Outcome assessment:-}

Weevaluated patient-defined outcome as improved, stabilised and worsened on the basis of postoperative follow up during the reviews. Any improvement from the presenting complains was considered as IMPROVED. Stabilised was defined as non-progression of complaints following the procedure. Any worsening of symptoms was to be taken as WORSENED.

\section{Results and Discussion:-}

Out of the total of 28 patients undergoing posterior fossa decompression for Chiari 1 malformation, the mean age of presentation was 24.5 years. 13 patients were male and 15 were female. Headache was the presenting complaint in all the 28 patients with classicialchiari type of headache in 24 and atypical presentation like generalised or fronto temporal headache in 4 patients. Features suggestive of myelopathy were seen in 14 patients. Scoliosis was present in 4 patients and charcot's joint in 4 patients (as shown in table 1). Radiological findings found were syringomyelia in 14patients interhemispheric cyst in 2 patients, carpus callosal agenesis in 4 patients, block vertebra involving $\mathrm{C} 2 \mathrm{C} 3$ in 1 patient and hydrocephalus in 3 patients (as shown in table 2).

Based on these presentations, clinical grading was done as grade 1 - typical presentation, grade 2 - atypical presentation, grade 3 - predominance of myelopathic features. Table 3 shows the distribution of patients based on the clinical grading. Radiological grading was done on the basis of syrinx. If the diameter of the syrinx was greater than $6 \mathrm{~mm}$, it was grade B and if it was less than $6 \mathrm{~mm}$ or absent, it was considered as grade A as shown in table 4. Patients were graded in to 3 based on chiari severity index. Grade 1 as clinical grade 1 , Grade 2 as clinical grade $2 / 3$ + radiological grade A, Grade 3 as clinical grade 2/3 + radiological grade B. There were 14 patients in grade 1 of chiari severity index, 4 patients in grade 2 of chiari severity index and 10 patients in grade 3 of chiari severity index. All the patients underwent posterior fossa decompression with removal of posterior arch of $\mathrm{C} 1$ with lax duroplasty. The 3 patients with hydrocephalus underwent ventriculoperitoneal shunt procedure followed by PFD. Postoperatively, csf leak was observed in 1 patient, aseptic meningitis in 1 patient, pseudomenngocele in 3 patients and hydrocephalus in 1 patient. Postoperative period was uneventful in 22 patients.

Postoperative outcome categorised as Improved (18 patients 64.2\%), Stabilised (9 patients 32.1\%) and worsened (1 patient $0.35 \%$ ) as shown in table 5 .

\section{Conclusion:-}

Posterior fossa decompression with lax duroplasty despite its complexity of the procedure is safe and effective way of reducing the symptomatology of chiari malformations with a lesser complication rate.

Table 1:-showing the distribution of symptoms.

\begin{tabular}{|l|l|l|}
\hline \multicolumn{1}{|c|}{ Symptoms } & No Of Patients & Percentage \\
\hline Headache & 32 & $100 \%$ \\
Occipital & 26 & \\
Frontotemporal headache & 6 & $44 \%$ \\
\hline Dissociated/ suspended sensory loss & 14 & $44 \%$ \\
\hline Spasticity of lower limbs & 14 & $38 \%$ \\
\hline Small muscle wasting of hands & 12 & \\
\hline Bladder / bowel disturbances & - & \\
\hline Trigeminal neuralgia & 1 & $12.5 \%$ \\
\hline Scoliosis & 4 & $12.5 \%$ \\
\hline Charcot joint & 4 & \\
\hline
\end{tabular}


Table 2:-showing the MRI findings

\begin{tabular}{|l|l|}
\hline $\begin{array}{l}\text { Mri } \\
\text { Findings }\end{array}$ & No Of Patients \\
\hline Syringomyelia & 17 \\
\hline $\begin{array}{l}\text { Interhemispheric } \\
\text { cyst }\end{array}$ & 2 \\
\hline $\begin{array}{l}\text { Corpus callosal } \\
\text { agenesis }\end{array}$ & 4 \\
\hline Block c2- c3 body & 1 \\
\hline Hydrocephalus & 3 \\
\hline
\end{tabular}

Table 3:- showing the distribution of patients on clinical grading.

\begin{tabular}{|l|l|}
\hline Clinical grade & Number of patients \\
\hline $\begin{array}{l}1 \text { (typical } \\
\text { presentation) }\end{array}$ & 12 \\
\hline $\begin{array}{l}2 \text { (atypical } \\
\text { presentation) }\end{array}$ & 2 \\
\hline 3 (myelopathy) & 14 \\
\hline
\end{tabular}

Table 4:-showing radiological grading based on syrinx

\begin{tabular}{|l|l|}
\hline $\begin{array}{l}\text { Radiological } \\
\text { grade }\end{array}$ & Number of patients \\
\hline $\begin{array}{l}\text { A (No syrinx } \\
\text { or syrinx } \\
<6 \mathrm{~mm})\end{array}$ & 18 \\
\hline $\begin{array}{l}\text { B (Syrinx }> \\
6 \mathrm{~mm})\end{array}$ & 10 \\
\hline
\end{tabular}

Table 5:-showing postoperative outcome following PFD

\begin{tabular}{|l|l|l|l|l|}
\hline C.S.I & Number of patients & \multicolumn{3}{|c|}{ Postoperative outcome } \\
& & Improved & 2 & - \\
\hline 1 & 14 & 12 & 3 & 1 \\
\hline 2 & 4 & - & 4 & - \\
\hline 3 & 10 & 6 & $9(34.1 \%)$ & 1 \\
\hline Total & 28 & $18(64.2 \%)$ & & worsened \\
\hline
\end{tabular}

Figure 1:-showing preoperative and postoperative scans following successful posterior fossa decompression
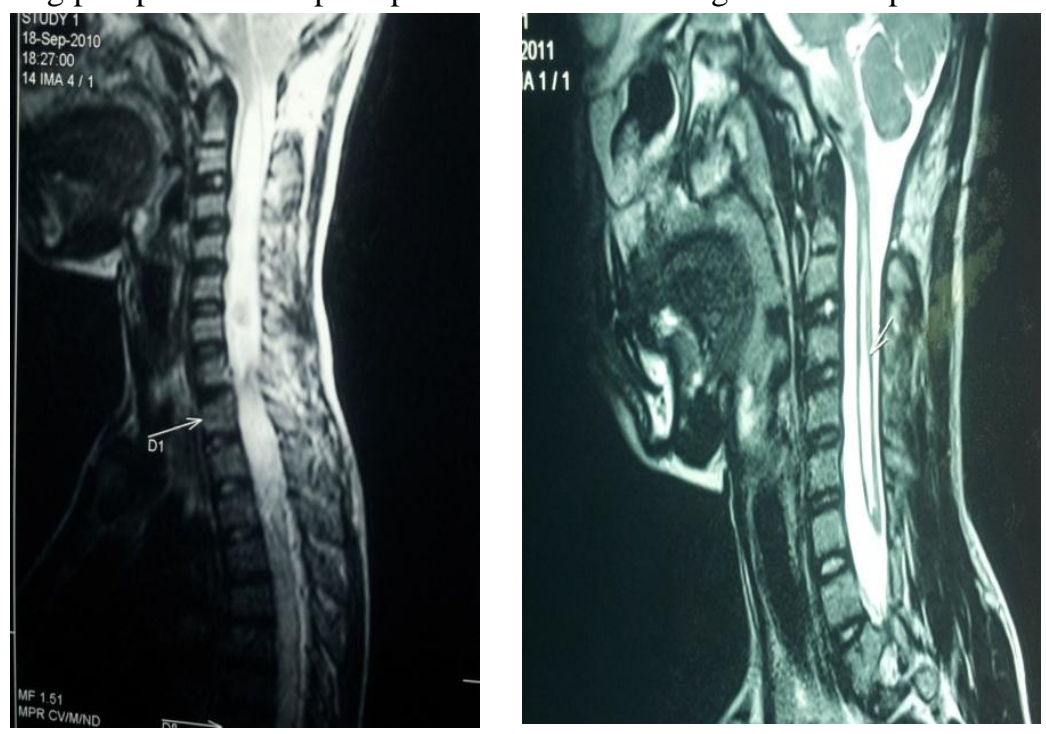
Figure 2:-showing preoperative and postoperative scans following successful posterior fossa decompression
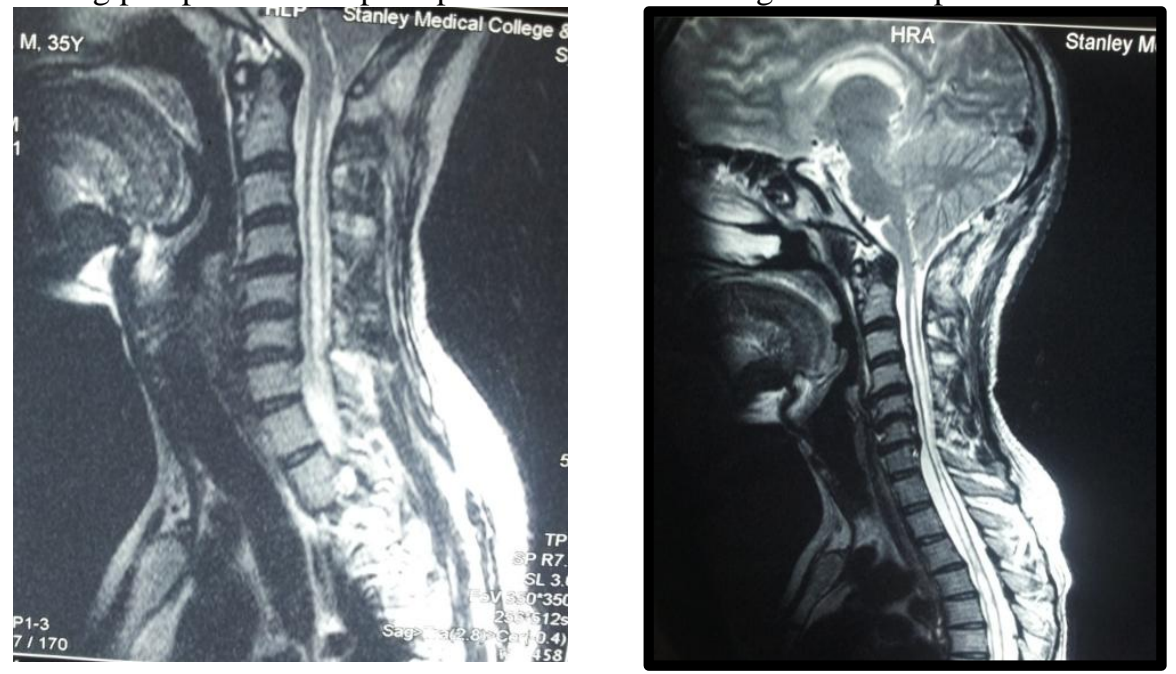

\section{References:-}

1. Meadows J,KrautM,Guarnieri M, Haroun RI, Carson BS. Asymptomatic Chiari Type I malformations identified on magnetic resonance imaging. J Neurosurg. 2000;92(6):920-926.

2. Strahle J, Muraszko KM, Kapurch J, Bapuraj JR, Garton HJ, Maher CO. Chiari malformation Type I and syrinx in children undergoing magnetic resonance imaging. J NeurosurgPediatr. 2011;8(2):205-213.

3. Durham SR, Fjeld-Olenec K. Comparison of posterior fossa decompression with and without duraplasty for the surgical treatment of Chiari malformation type I in pediatric patients: a meta-analysis. J NeurosurgPediatr. 2008;2(1):42-49.

4. Hankinson T, Tubbs RS, Wellons JC. Duraplasty or not? an evidence-based review of the pediatric Chiari I malformation. Childs Nerv Syst. 2011;27(1):35-40.

5. Aliaga L, Hekman KE, Yassari R, et al. A novel scoring system for assessing Chiari malformation type I treatment outcomes. Neurosurgery. 2012;70(3):656-664; discussion 664-665.

6. Mueller DM, Oro JJ. The Chiari symptom profile: development and validation of aChiari-/syringomyeliaspecificquestionnaire.JNeurosciNurs.2013;45(4):205-210.

7. Yarbrough CK, Greenberg JK, Smyth MD, Leonard JR, Park TS, Limbrick DD Jr. External validation of the Chicago Chiari outcome scale. J NeurosurgPediatr. 2014;13(6):679-684.

8. Godil SS, Parker SL, Zuckerman SL, Mendenhall SK, McGirt MJ. Accurately measuringoutcomesaftersurgeryforadultChiariImalformation:determiningthe most valid and responsive instruments. Neurosurgery. 2013;72(5):820-827.

9. Stovner LJ, Rinck P. Syringomyelia in Chiari malformation: relation to extent of cerebellar tissue herniation. Neurosurgery. 1992;31(5):913-917; discussion 917.

10. Godzik J, Kelly MP, Radmanesh A, et al. Relationship of syrinx size and tonsillar descent to spinal deformity in Chiari malformation Type I with associated syringomyelia. J NeurosurgPediatr. 2014;13(4):368-374.

11. Smoker WR, Khanna G. Imaging the craniocervical junction. Childs Nerv Syst. 2008;24(10):1123-1145.

12. Tubbs RS, Iskandar BJ, Bartolucci AA, Oakes WJ. A critical analysis of the Chiari 1.5 malformation. J Neurosurg. 2004;101(2 suppl):179-183. 